\title{
Introduction to the Special Section TC21 of the XXI IMEKO World Congress 2015
}

\section{Franco Pavese}

Torino, Italy

Section: EDITORIAL

Citation: Franco Pavese, Introduction to the Special Section TC21 of the XXI IMEKO World Congress 2015, Acta IMEKO, vol. 5, no. 3, article 1, November 2016, identifier: IMEKO-ACTA-05 (2016)-03-01

Section Editor: Franco Pavese, Italy

Received October 20, 2016; In final form October 20, 2016; Published November 2016

Copyright: ( 2016 IMEKO. This is an open-access article distributed under the terms of the Creative Commons Attribution 3.0 License, which permits unrestricted use, distribution, and reproduction in any medium, provided the original author and source are credited

Corresponding author: Franco Pavese, email: frpavese@gmail.com

\section{Dear Reader,}

this Special Issue includes five papers, originating from subject matters presented at the XXI IMEKO World Congress 2015 held in Prague, during sessions organized by Technical Committee 21 on Mathematical Tools for Measurements, and selected for publication in Acta IMEKO.

The first is a short review of concepts of probability related to measurement.

The paper of Cundeva-Blajer is devoted to optimization methods in electrical metrology.
The paper of Shirono concerns the maximum likelihood concept applied to evaluate the uncertainty in proficiency tests.

The paper of Volosnikov illustrates the use of neural networks for error correction in dynamic measurements.

The paper of Witkovsky proposes an alternative tool to form the probability distribution of output quantities by numerical inversion in linear models.

Franco Pavese

Guest Editor

IMEKO TC21, Chair 